\title{
Elevated cyclin A associated kinase activity promotes sensitivity of metastatic human cancer cells to DNA antimetabolite drug
}

\author{
JIN WANG ${ }^{1}$, HAILIN YIN $^{1}$, ASHWINI PANANDIKAR $^{1}$, VARSHA GANDHI $^{2}$ and SUBRATA SEN ${ }^{1,3}$ \\ Departments of ${ }^{1}$ Translational Molecular Pathology and ${ }^{2}$ Experimental Therapeutics, \\ The University of Texas M.D. Anderson Cancer Center; ${ }^{3}$ Program in Human and Molecular Genetics, \\ University of Texas Graduate School of Biomedical Sciences, Houston, TX 77030, USA
}

Received March 31, 2015; Accepted May 4, 2015

DOI: $10.3892 /$ ijo.2015.3037

\begin{abstract}
Drug resistance is a major obstacle in successful systemic therapy of metastatic cancer. We analyzed the involvement of cell cycle regulatory proteins in eliciting response to $\mathrm{N}$ (phosphonoacetyl)-L-aspartate (PALA), an inhibitor of de novo pyrimidine synthesis, in two metastatic variants of human cancer cell line MDA-MB-435 isolated from lung (L-2) and brain (Br-1) in nude mouse, respectively. L-2 and $\mathrm{Br}-\mathrm{l}$ cells markedly differed in their sensitivity to PALA. While both cell types displayed an initial S phase delay/arrest, Br-l cells proliferated but most L-2 cells underwent apoptosis. There was distinct elevation in cyclin A, and phosphorylated $\mathrm{Rb}$ proteins concomitant with decreased expression of bcl-2 protein in the PALA treated L-2 cells undergoing apoptosis. Markedly elevated cyclin A associated and cdk2 kinase activities together with increased E2F1-DNA binding were detected in these L-2 cells. Induced ectopic cyclin A expression sensitized Br-l cells to PALA by activating an apoptotic pathway. Our findings demonstrate that elevated expression of cyclin A and associated kinase can activate an apoptotic pathway in cells exposed to DNA antimetabolites. Abrogation of this pathway can lead to resistance against these drugs in metastatic variants of human carcinoma cells.
\end{abstract}

Correspondence to: Professor Subrata Sen, Department of Translational Molecular Pathology, Unit 2951, The University of Texas M.D. Anderson Cancer Center, 1515 Holcombe Boulevard, Houston, TX 77030, USA

E-mail: ssen@mdanderson.org

Abbreviations: PALA, N(phosphonoacetyl)-L-aspartate; Mtx, methotrexate; $\mathrm{BHK}$, baby hamster kidney; $\mathrm{Rb}$, retinoblastoma protein; PAGE, polyacrylamide gel electrophoresis

Key words: drug resistance, cyclin A, N(phosphonoacetyl)-L-aspartate, apoptosis pathway

\section{Introduction}

Drug resistance is a major obstacle in successful chemotherapy of metastatic breast cancer and most patients with drug resistant metastatic cancer succumb to the disease. Therefore, it is important to investigate the genetic basis of drug resistance in metastatic cancer cells to design effective therapy of advanced stage disease and improve their clinical outcome. Increased genetic instability leads to progressive metastasis of tumors with simultaneous acquisition of resistance to chemotherapeutic drugs. Recent advances in understanding the mode of action of anticancer drugs indicate that regardless of their diverse nature, most of them elicit apoptosis in the target cells $(1,2)$. The genetic changes which inactivate apoptotic pathways during tumor development make tumor cells resistant to drugs. Apoptosis is associated with activation of a number of genes that mediate the transition from quiescence to proliferative growth $(3,4)$. Premature activation of a subset of protein kinases, normally active in mitosis, has been implicated as critical events in the apoptosis process $(5,6)$.

Cyclin proteins associating with and activating cyclin dependent kinases are central to the control of cell proliferation in eukaryotic cells. These proteins are involved at critical nodal points, shared by pathways regulating both cellular proliferation as well as apoptosis (7-13). Phosphorylation of $\mathrm{pRb}$ by cyclin D/cdk4, cyclin E/cdk2 and/or cyclin A/cdk2 during Gl/S transition releases the transcription factor E2F1 which directs the timely expression of cell cycle controlling genes regulating initiation and orderly progression of $S$ phase $(14,15)$. Cyclin A kinase through binding and phosphorylation of the transcription factor E2F1 suppresses expression of specific $S$ phase genes. The regulation of E2F1 DNA binding and transactivation has been proposed to represent an $\mathrm{S}$ phase checkpoint which when disrupted due to decreased cyclin $\mathrm{A} / \mathrm{cdk} 2$ activity results in $\mathrm{S}$ phase delay/arrest followed by regrowth or apoptosis (16). Enhanced DNA binding of hypophosphorylated E2F1 has been correlated with increased sensitivity of human tumor cells to cytotoxic drug and ionizing radiation treatments $(17,18)$.

Two metastatic variants of the human cancer cell line (MDAMB-435) isolated from lung and brain metastasis in nude 
mice (19) demonstrate markedly different levels of sensitivity to antimetabolite chemotherapeutic drugs. In this study, we investigated the involvement of cell cycle regulatory proteins in eliciting differential response in these two variants to the antimetabolite drug PALA. PALA is a potent inhibitor of aspartate transcarbamoyl transferase, the enzyme catalyzing the second step of de novo pyrimidine biosynthesis.

We observed elevation of cyclin A expression and activation of its catalytic subunit kinase in the drug sensitive L-2 cells undergoing apoptosis but not in the resistant Brl cells. Further, we demonstrated that induced ectopic expression of cyclin A was sufficient to cause apoptosis in the resistant $\mathrm{Br} 1$ cells when exposed to PALA. In cells undergoing apoptosis, elevated cyclin A expression and kinase activities also correlated with increased E2Fl DNA binding activity. Therefore, this study provides evidence that apoptotic response in antimetabolite drug-treated tumor cells involves enhanced cyclin A/cdk2 activity concomitant with increased E2Fl DNA binding activity. Taken together these results suggest that cyclin A and associated kinase activity are regulators of a checkpoint response that is activated in drug-treated cells leading to induction of apoptosis.

\section{Materials and methods}

Cell lines and drug selection. Br-1 and L-2 cell lines established from metastasis in nude mouse injected with the human tumor cell line MDA-MB-435 were provided by Dr Janet E. Price of the Department of Cancer Biology, The University of Texas M.D. Anderson Cancer Center. MDA-MB-435, isolated from plural effusion of a 31-year-old breast cancer patient, was later reported to show similarity with melanocyte/melanoma cells based on gene expression profiling data. The $\mathrm{Br}-\mathrm{l}$ cell line was established from a brain metastasis while L-2 cells were selected by two cycles of growth and metastasis to lung in nude mice (19). Cell lines were maintained in Dulbecco's modified Eagle's medium supplemented with $10 \%$ dialyzed FBS (Gibco, Grand Island, NY, USA). The cells were grown on plastic and incubated in $5 \% \mathrm{CO}_{2}$ in air at $37^{\circ} \mathrm{C}$ in a humidified incubator. Three independent clones isolated from the L-2 (L-2, L-2-1, L-2-2) and Br-1 (Brl-3prl, Brl-3pr2, Brl3pr3) were utilized in this study. Population doubling time, for each of these cell lines were estimated to be $\sim 24 \mathrm{~h}$. Drug resistance levels and proliferative response to drug treatment among the clonal isolates from each cell type variant were very similar.

Cell lines were tested for their potential to acquire resistance against the DNA antimetabolite drug PALA. Frequency of drug resistant cells developing at $5 \mathrm{xLD}_{50}$ concentration of the drug were $<10^{-5}$ for L- 2 and $<10^{-3}$ for Br-1 cells. PALA was obtained from Drug synthesis Branch (Division of Cancer Treatment, National Cancer Institute). At $20 \mathrm{xLD}_{50}, \mathrm{Br}-1$ cells gave rise to resistant colonies but L-2 cells did not. Further experiments to study early proliferative response and cell cycle regulatory protein expression were done with cells exposed to $20 \mathrm{xLD}_{50}$ of PALA $(300 \mu \mathrm{M})$.

Drug treatment. L-2 and Brl-3prl cells were plated at a density of $1-2 \times 10^{6}$ and $48 \mathrm{~h}$ later $300 \mu \mathrm{M}$ of PALA was added. Cells were initially harvested after 12, 24 and $48 \mathrm{~h}$ of PALA treatment for flow cytometry analysis and oligonucleosomal DNA analyses. In another set of experiments, cells treated for $48 \mathrm{~h}$ were washed, re-plated in drug-free medium and harvested at $0,4,10,24$ and $48 \mathrm{~h}$ for flow cytometry, oligonucleosomal DNA analysis and protein analysis. Cells harvested immediately after $48 \mathrm{~h}$ of PALA at $0 \mathrm{~h}$ were considered as those representing the control time point.

Growth rate analysis. Exponentially growing L-2 and Brl-3prl were plated in $60-\mathrm{mm}$ dishes at a cell density of $3 \times 10^{5}$. After $48 \mathrm{~h}$, regular medium was replaced with medium containing $300 \mu \mathrm{M}$ of PALA $\left(20 \mathrm{xLD}_{50}\right)$. PALA was washed off after $48 \mathrm{~h}$ and regular medium was added. Cells were counted from day 0 through day 5 for every $24 \mathrm{~h}$ with trypan blue staining.

Flow cytometry analysis. Approximately $1 \times 10^{6}$ cells were washed with phosphate buffered saline (PBS), fixed overnight in $70 \%$ ethanol, stained with propidium iodide (final concentration was $0.01 \mu \mathrm{g} / \mathrm{ml}$ in PBS and analyzed on a FACScan cytometer (Becton Dickinson). Resolution of G1, S and G2/M phases was done with LYSIS II analysis software (Becton Dickinson).

Effect of PALA on cellular nucleotides. To determine the PALA-mediated perturbation in the ribonucleotide pools, each cell line was incubated with $300 \mu \mathrm{M}$ PALA for $48 \mathrm{~h}$. After treatment cells were washed with phosphate-buffered saline, enumerated with Coulter counter analyzer, and mean cell volume was determined with the Coulter channelyzer (Coulter Electronics Inc., Hialeah, FL, USA). Nucleotides were extracted from cells by standard procedures using HC104 before (control) and $48 \mathrm{~h}$ after incubation with $300 \mu \mathrm{M}$ PALA. Ribonucleotides were separated using an anion-exchange Partisil-10 SAX (Waters Corp., Milford, MA, USA) column by high-pressure liquid chromatography (45). The intracellular concentration was calculated and expressed as the quantity of nucleotides contained in the extract from a given number of cells of a determined mean volume. This calculation assumes that nucleotides are uniformly distributed in total cell water. In general, the lower limit of sensitivity of this assay was $50 \mathrm{pmol}$ in an extract of $1 \times 10^{7}$ cells, corresponding to a cellular concentration of $\sim 2.5 \mu \mathrm{M}$.

Oligonucleosomal DNA analysis. For DNA fragmentation assay, both adherent and non-adherent cells were washed in PBS and lysed in $100 \mu \mathrm{l}$ ice cold PBS and $400 \mu 1$ lysis buffer (Tris-EDTA, $0.1 \%$ Triton X-100) on ice for $20 \mathrm{~min}$. The supernatant containing fragmented DNA was isolated by centrifuging and precipitating with $\mathrm{NaCl}$ and isopropanol at $-20^{\circ} \mathrm{C}$ overnight. The pellets were resuspended in $150 \mu \mathrm{l}$ of buffer containing $10 \mathrm{mM}$ Tris $\mathrm{pH} 7.8,25 \mathrm{mM}$ EDTA, $0.5 \%$ SDS and $100 \mu \mathrm{g}$ of proteinase $\mathrm{K}$ at $37^{\circ} \mathrm{C}$ overnight. The samples were extracted twice with phenol:chloroform (1:1 by volume). The low molecular weight DNA was recovered by ethanol precipitation, resuspended in $25 \mu \mathrm{l}$ Tris-EDTA, and treated with RNAse A for $2 \mathrm{~h}$ at $37^{\circ} \mathrm{C}$ prior to electrophoresis on $1.8 \%$ agarose gel.

Western blots. Total cell lysates were prepared by lysing cells in lysis buffer (50 mM Tris pH 7.4, 5 mM EDTA, $250 \mathrm{mM}$ $\mathrm{NaCl}, 50 \mathrm{mM} \mathrm{NaF}, 1 \mu \mathrm{g} / \mathrm{ml}$ leupeptin and aprotinin) at $4^{\circ} \mathrm{C}$ 
for $20 \mathrm{~min}$. The protein concentration of supernatant was determined by Bio-Rad protein assay. Equal amount of protein was resolved on $8-10 \%$ SDS-PAGE gels and transferred to Immobilon P (Millipore). Membranes were blocked with 5\% non-fat milk and probed with antibodies against p53, Rb, p21, myc, cyclin A, cyclin E, cdc2, bcl-2 (Oncogene Science), cdk2 (Upstate Biotechnology). After incubation of blot with horseradish peroxidase-conjugated secondary antibody, reactive polypetides were detected by the enhanced chemiluminescence (ECL) system (Amersham).

Hl kinase activity. Cyclin A, cyclin E, cdc2 and cdk 2 associated kinase activities were measured in vitro after immunoprecipitation, using histone (Boehringer Mannheim) as a substrate. Total cell lysates were made from $300 \mu \mathrm{M}$ PALA treated cells at indicated time points. For each immunoprecipitation $50 \mu \mathrm{g}$ of protein saturated with proper antibody was incubated with protein $\mathrm{G}+\mathrm{A}$ agarose beads (Oncogene Science) overnight at $4^{\circ} \mathrm{C}$. After extensive washing in lysis and kinase buffer the beads were assayed for $30 \mathrm{~min}$ at $37^{\circ} \mathrm{C}$ in kinase buffer $(50 \mathrm{mM}$ Tris pH 7.4, $10 \mathrm{mM} \mathrm{MgCl} 2,1 \mathrm{mM}$ DTT, $50 \mu \mathrm{M}$ ATP, $1 \mu \mathrm{Ci}$ of $\left(\gamma^{32} \mathrm{P}\right.$-ATP $)$ containing $1 \mathrm{mg} / \mathrm{ml}$ substrate. Kinase reactions were analyzed by autoradiography following $12 \%$ SDS-PAGE and quantitation with the help of phosphorimager.

E2F1 DNA binding activity assay. Cells were washed in PBS containing $1 \mathrm{mM}$ PMSF, and then harvested to prepare nuclear proteins for assessing E2Fl DNA binding activity by gel retardation assay (46). Harvested cells were washed in wash buffer (20 mM HEPES, $2 \mathrm{mM}$ DTT, $2 \mathrm{mM} \mathrm{MgCl}$, $1 \mathrm{mM}$ PMSF, $2 \mu \mathrm{g} / \mathrm{ml}$ leupeptin, $1 \mu \mathrm{g} / \mathrm{ml}$ aprotinin) and lysed in wash buffer containing $0.2 \%$ Triton X-100 by incubation on ice for $10 \mathrm{~min}$. Nuclei were then collected by centrifugation at $13,000 \mathrm{rpm}$ for $10 \mathrm{sec}$ at $4^{\circ} \mathrm{C}$. The nuclei were resuspended in $50 \mu \mathrm{l}$ of nuclear extraction buffer (20 mM HEPES, $2 \mathrm{mM} \mathrm{MgCl}_{2}, 2 \mathrm{mM}$ DTT, $420 \mathrm{mM} \mathrm{KCl,} \mathrm{25 \%} \mathrm{glycerol,} 1 \mathrm{mM}$ EDTA and protease inhibitors) and incubated on ice for $20 \mathrm{~min}$. Cellular debris was removed by centrifugation at $13,000 \mathrm{rpm}$ for $5 \mathrm{~min}$ at $4^{\circ} \mathrm{C}$. The protein/DNA interaction assay was performed by preincubating $5 \mu \mathrm{g}$ of nuclear proteins in a binding buffer (4\% Ficoll 400, $20 \mathrm{mM}$ HEPES pH 7-9, $2 \mathrm{mM} \mathrm{MgCl}_{2}, 0.5 \mu \mathrm{g}$ of salmon sperm DNA and $100 \mathrm{mM} \mathrm{KCl}$ ) for $10 \mathrm{~min}$ at room temperature. $\gamma^{32} \mathrm{P}$-ATP labeled E2 oligonucleotide probe (10 pmol) was then added and incubated at room temperature for $30 \mathrm{~min}$. The reaction products were resolved on a $4 \%$ polyacrylamide gel in $0.5 \times \mathrm{TBE}$ run at $160 \mathrm{~V}$ at $4^{\circ} \mathrm{C}$ for $2-3 \mathrm{~h}$. Gels were dried and exposed to X-ray film.

Brl transfection with pMTCyc A. Cells bearing a $\mathrm{Zn}^{2+}$ responsive cyclin A construct were generated by transfecting the pMTCyc A plasmid into Brl-3pr1 cells (Br-1 pMTCyc A). pMTCyc A contains a $2.3 \mathrm{~kb}$ EcoR1 fragment of human cyclin A cDNA downstream of a sheep metallothionein promoter and a neomycin-resistant marker gene. Thirty randomly selected clones were expanded and screened by southern blot analysis of total genomic DNA with cyclin A probe. Four positive clones were analyzed further to see inducibility of the cyclin A transgene. Two of these clones showed distinct-induction of cyclin A expression in the presence of $100 \mu \mathrm{M} \mathrm{Zn}^{2+}$. Expression of induced cyclin $\mathrm{A}$ in the clones was determined after induction with $100 \mu \mathrm{M}$ of $\mathrm{Zn}^{2+}$ for different time intervals. Total cell lysates were prepared and Western blot analysis was done as described above. Oligonucleosomal DNA fragmentation analysis of clones was done as described above after treatment with $300 \mu \mathrm{M}$ PALA for $48 \mathrm{~h}$ and simultaneous induction of cyclin A with $100 \mu \mathrm{M} \mathrm{Zn}^{2+}$ for $9 \mathrm{~h}$.

\section{Results}

Growth rate analysis in L-2 and Brl-3prl. Effect of $48 \mathrm{~h}$ PALA treatment at $20 \mathrm{xLD}_{50}$ on the growth rate of the two cell types, was assessed over a 5 day period. L-2 and Brl-3prl showed clear difference in their growth potential following drug treatment (Fig. 1A). After an initial growth arrest in both cell lines, Brl-3prl recovered and continued proliferation whereas L-2 cells failed to grow. These results demonstrated that the differential levels of drug sensitivity in the two cell types were manifested in their markedly different proliferation pattern within the first $24 \mathrm{~h}$ after exposure to the drug.

Cell cycle distribution pattern following PALA administration. We investigated how PALA exposure affected proliferative pattern through the cell cycle in the two cell types. Untreated cells of both variants showed a similar cell cycle distribution pattern (C in Fig. 1B). It was noted that both cell lines treated for $48 \mathrm{~h}$ showed progressive accumulation of cells in $\mathrm{S}$ phase. However, the difference in cell cycle stage specific distribution pattern of the cells became evident following release from PALA treatment of L-2 and Brl-3prl cells. At the end of $48 \mathrm{~h}$ treatment (or same as $0 \mathrm{~h}$, Fig. 1B), cells were predominantly in $\mathrm{S}$ phase in both the cell lines, although slightly higher proportion of cells in S phase were noted in L-2 than Brl-3prl cells. At $4 \mathrm{~h}$ post-treatment $\mathrm{S}$ phase cell population showed further increase in the two cell types but at $10 \mathrm{~h}$, there was a decline in the percentage of cells in $\mathrm{S}$ phase in both cases with increase in $\mathrm{G} 2 / \mathrm{M}$ phase cells. At $24 \mathrm{~h}$ post-treatment cell cycle distribution profile of L-2 cells showed more cells in G2/M phase than in $\mathrm{G} 1$ or $\mathrm{S}$ phases. Brl-3prl cells, however, revealed a pattern similar to the one seen in untreated controls. In view of our findings that there was significant loss in proliferative capacity as well as decrease in the number of surviving L-2 cells after PALA treatment, we compared the percentage of apoptotic cells using the sub-G1 FACS assay in both cell types.

There was significant cell death detected in L-2 cells immediately after $48 \mathrm{~h}(11 \%, 0 \mathrm{~h}$, Fig. 1C) PALA treatment. Following a lower incidence $(4 \%)$ at $4 \mathrm{~h}$, there was a second wave of apoptosis induction detected in the L-2 cells at $10 \mathrm{~h}(9 \%)$ and $24 \mathrm{~h}(21 \%)$. Brl-3prl cells on the other hand did not undergo significant apoptosis up to $10 \mathrm{~h}$ post-treatment but showed slight increase $(5 \%)$ at $24 \mathrm{~h}$ post-treatment. These results suggested that both cell types underwent an initial $\mathrm{S}$ phase delay/arrest following PALA treatment. Except for a small percentage, most Brl-3prl cells recovered and proliferated but increasing number of L-2 cells progressively underwent apoptosis.

DNA fragmentation assay. Apoptosis in response to PALA treatment was assayed by the presence of oligonucleosomal DNA fragments in the two cell types. No significant DNA fragmentation was observed in L-2 cells treated with PALA for less than $48 \mathrm{~h}$. At the end of $48 \mathrm{~h}$ (time $0 \mathrm{~h}$, Fig. 1D) 

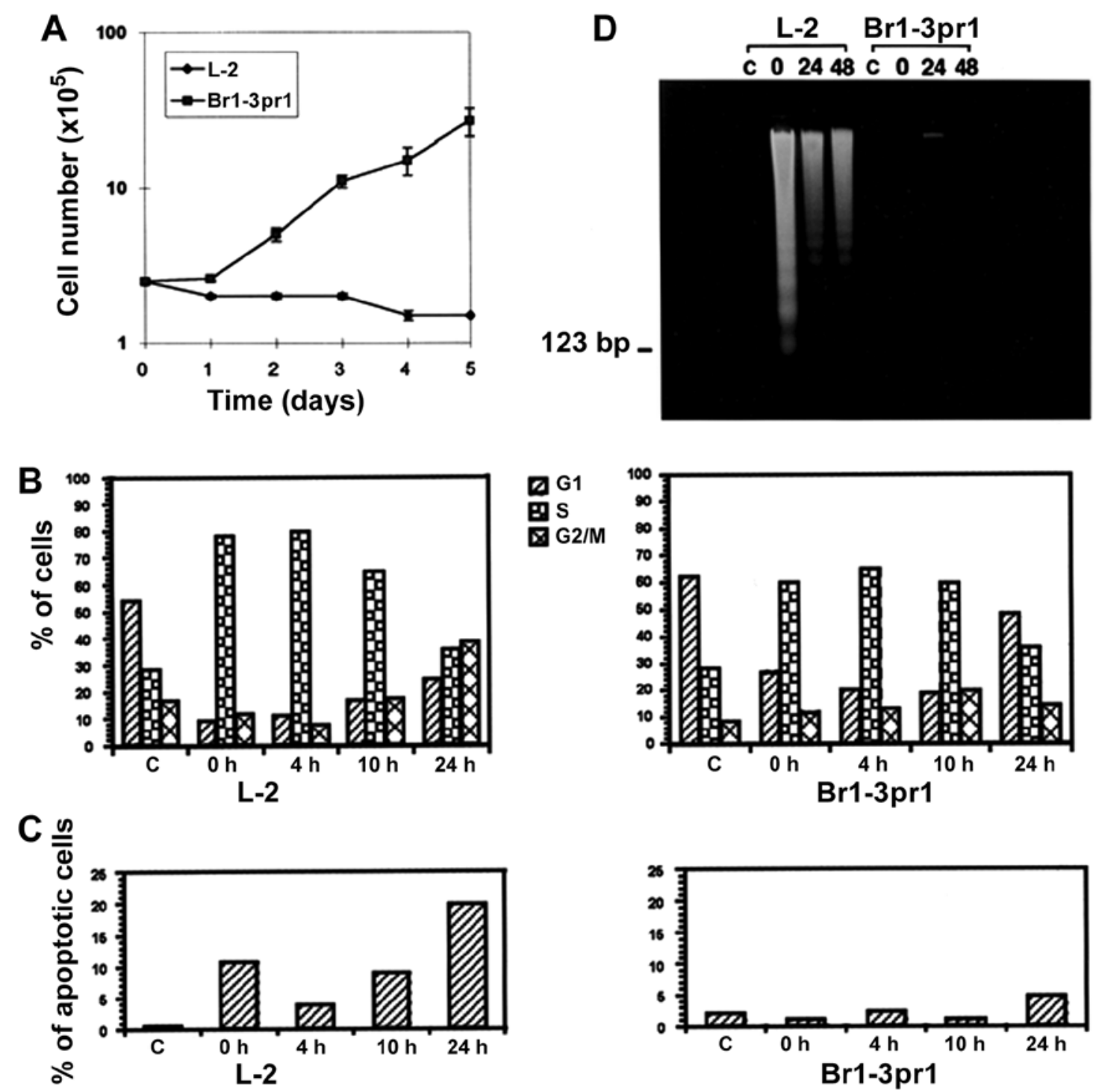

Figure 1. Cytotoxicity analysis of $300 \mu \mathrm{M}$ PALA treatment on L-2 and Brl-3prl cells. (A) Growth inhibition of PALA treated cells analyzed by trypan blue dye. (B) Cell cycle analysis in the two variants prior to treatment (C) or after $48 \mathrm{~h}$ treatment with PALA at the indicated times. (C) Percentage of apoptotic cells at different time points. (D) DNA fragmentation analysis of untreated (C) or PALA treated cells at different time intervals.

significant DNA fragmentation indicative of apoptosis was observed in agreement with the flow cytometry data reported earlier. Brl-3prl cells did not reveal any significant DNA fragmentation following PALA treatment at all the time points checked. These results reveal that L-2 cells treated for $48 \mathrm{~h}$ with PALA show progressive accumulation of cells in $\mathrm{S}$ phase and activation of an apoptotic pathway leading to cell death. Brl-3prl cells on the other hand showed a transient $S$ phase arrest and recovered to proliferate without significant evidence of apoptosis in these cells. L-2 cells from several dishes had to be pooled for all subsequent protein expression and kinase activity studies since massive apoptosis was induced in these cells following drug treatment.

Effect of PALA on cellular nucleotides. To determine if the apoptotic response of these cell lines to PALA treatment was due to differential effect on the nucleotide pools, cellular NTPs were quantitated in control (untreated cells) and in cells incubated with PALA for $48 \mathrm{~h}$. As presented in Table I, there was a significant reduction in the pyrimidine nucleotide pools in both
Table I. Effect of PALA on ribonucleotides in L-2 and Br1-3pr1 cells.

\begin{tabular}{lcc}
\hline & \multicolumn{2}{c}{$\%$ of Control NTP, Mean \pm SD } \\
\cline { 2 - 3 } NTP & L-2 & Br1-3pr1 \\
\hline CTP & $7.1 \pm 2.7$ & $7.5 \pm 2.2$ \\
UTP & $3.3 \pm 0.2$ & $4.7 \pm 1.2$ \\
ATP & $141.7 \pm 18.8$ & $161.6 \pm 28.5$ \\
GTP & $123.0 \pm 8.0$ & $159.2 \pm 31.5$
\end{tabular}

The changes in the levels of nucleotides in PALA treated cells are expressed as $\%$ of control values. Data points are mean and SD of three separate experiments.

cell lines after PALA treatment. CTP pool size was lowered to $<8 \%$ in both cases $(\mathrm{p}=0.024$ for $\mathrm{L}-2$ and $\mathrm{p}=0.002$ for $\mathrm{Brl}-3 \mathrm{prl}$ 
Table II. Kinase activities in L-2 and Br1-3prl cells.

\begin{tabular}{|c|c|c|c|c|c|c|c|c|}
\hline \multirow[b]{2}{*}{ Kinase } & \multicolumn{4}{|c|}{ L-2 } & \multicolumn{4}{|c|}{ Br1-3pr1 } \\
\hline & Control & $4 \mathrm{~h}$ & $10 \mathrm{~h}$ & $24 \mathrm{~h}$ & Control & $4 \mathrm{~h}$ & $10 \mathrm{~h}$ & $24 \mathrm{~h}$ \\
\hline Cyclin A & 1 & 3.1 & 2.2 & 1.2 & 1 & 1.4 & 2.0 & 1.8 \\
\hline Cyclin E & 1 & 3.4 & 2.2 & 1.8 & 1 & 1.5 & 1.5 & 1.7 \\
\hline $\mathrm{Cdk} 2$ & 1 & 9.0 & 7.5 & 5.0 & 1 & 3.0 & 2.0 & 1.7 \\
\hline $\mathrm{Cdc} 2$ & 1 & 1.6 & 2.1 & 1.5 & 1 & 1.0 & 1.1 & 1.2 \\
\hline
\end{tabular}

Densitometric quantitation of the relative changes in the kinase activities. Control values of both L-2 and Brl-3prl were taken as 1.0 for normalization.
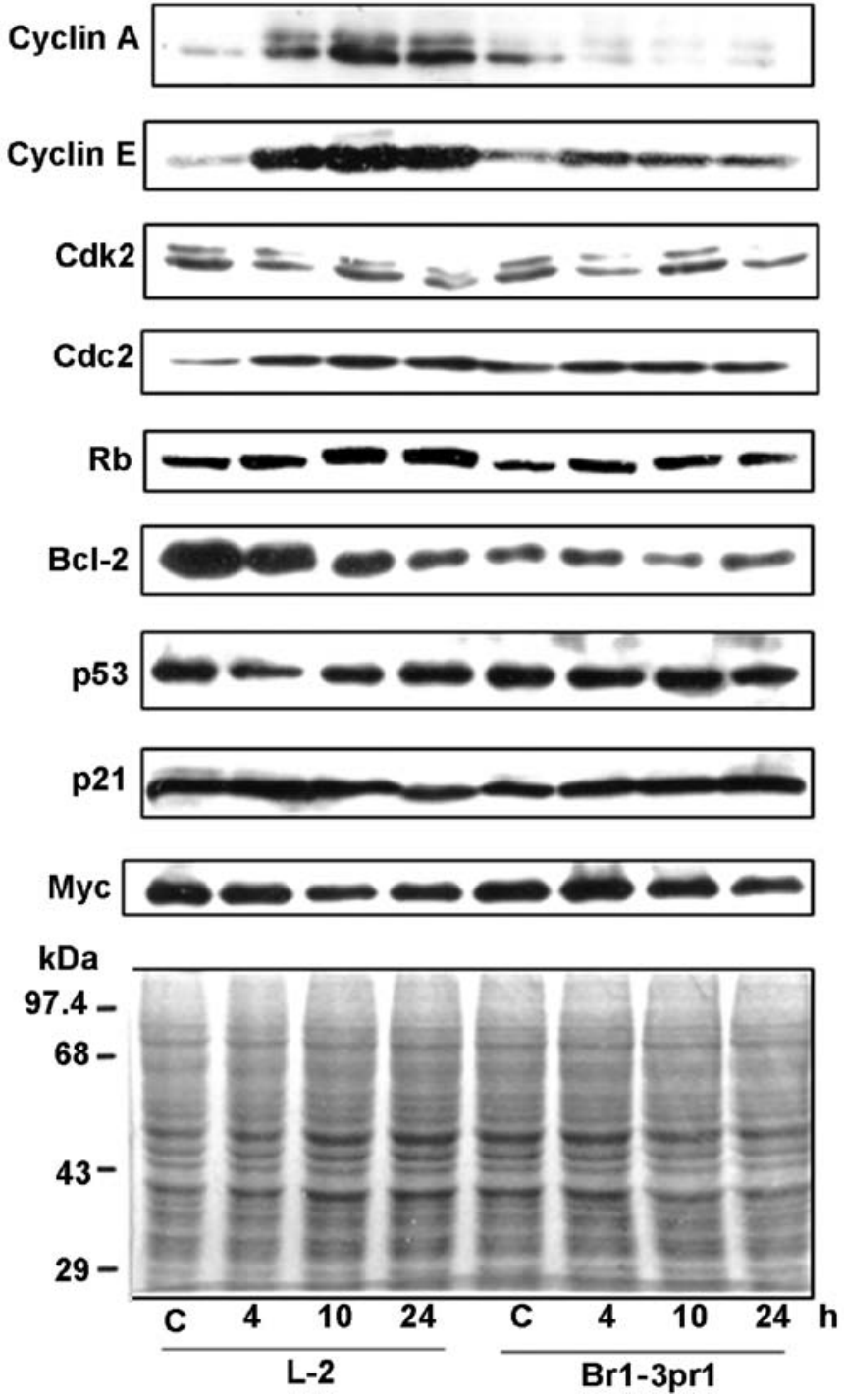

Figure 2. Expression of cell cycle regulatory proteins in cells after $300 \mu \mathrm{M}$ PALA treatment. Total cell extracts were from untreated (C) and cells treated for $48 \mathrm{~h}$ with PALA and then released in drug-free medium for indicated times $(4,10$ and $24 \mathrm{~h})$. The Coomassie blue stained gel reflects the comparable amount of protein loading.

cells). There was $>95 \%$ decrease in the concentration of UTP $(\mathrm{p}=0.018$ and 0.0002 for L-2 and Brl-3prl cells, respectively). In contrast to pyrimidine nucleotides, there was $30-60 \%$ increase in the purine nucleotide concentration. These data clearly demonstrated that the action of PALA in both these cell lines was comparable resulting in similar reduction in the pyrimidine NTPs.

Expression of cell cycle regulatory protein. The expression profile of cell cycle and apoptosis regulatory proteins after PALA treatment were assessed to evaluate if they correlated with induction of apoptosis process. In order to assess the pattern of expression of cell cycle regulatory proteins in L-2 cells undergoing apoptosis and Brl-3prl cells recovering to proliferate following $\mathrm{S}$ phase arrest, western blot analysis of p53, p21, Rb, c-myc, cyclin A, cyclin E, cdk2, cdc2 and bcl-2 was performed at different time intervals after release from $48 \mathrm{~h}$ treatment of PALA (Fig. 2). Compared to the untreated cells (C), no apparent effect in the levels of p53, p21 and myc proteins were observed in the two cell types. There was moderate difference in the level of phosphorylated $\mathrm{Rb}$ proteins seen in the two cell types. L-2 cells showed increased accumulation of phosphorylated $\mathrm{Rb}$ compared with $\mathrm{Brl}-3 \mathrm{prl}$ cells. Marked increase in the amount of cyclin A protein was detected in the L-2 cells undergoing apoptosis with the highest level detected at $10 \mathrm{~h}$ post-drug treatment. In contrast, there was no increase in the level of cyclin A seen in the Brl-3prl cells. Cyclin E protein was found elevated in the L-2 cells and Brl-3prl cells compared to their respective controls (lanes C). The increase in cyclin E protein in L-2 cells despite being more than that seen in Brl-3prl cells was not as significant as that seen for cyclin A protein, at similar time intervals.

Expression of both $\mathrm{cdk} 2$ and $\mathrm{cdc} 2$ proteins were also monitored. Cdc2 protein amount was elevated in drug-treated L-2 cells compared to the control at all the time points checked. There was no distinct alteration in the level of cdk2 protein detected in the cell types. L-2 demonstrated a gradual decrease in the expression of bcl-2 from 4 through $24 \mathrm{~h}$ post-treatment; whereas bcl-2 expression levels remained virtually unchanged in Brl-3prl cells. Taken together these data document that in contrast to proliferating Br1-3prl cells, apoptosis in PALA treated L-2 cells is accompanied with discrete changes in the levels of some proteins. These include increase in the cyclin A and cdc2 along with decline in the bcl-2 proteins.

Kinase activity assay. In order to determine if the levels of cyclins and kinases correlated with their associated kinase 


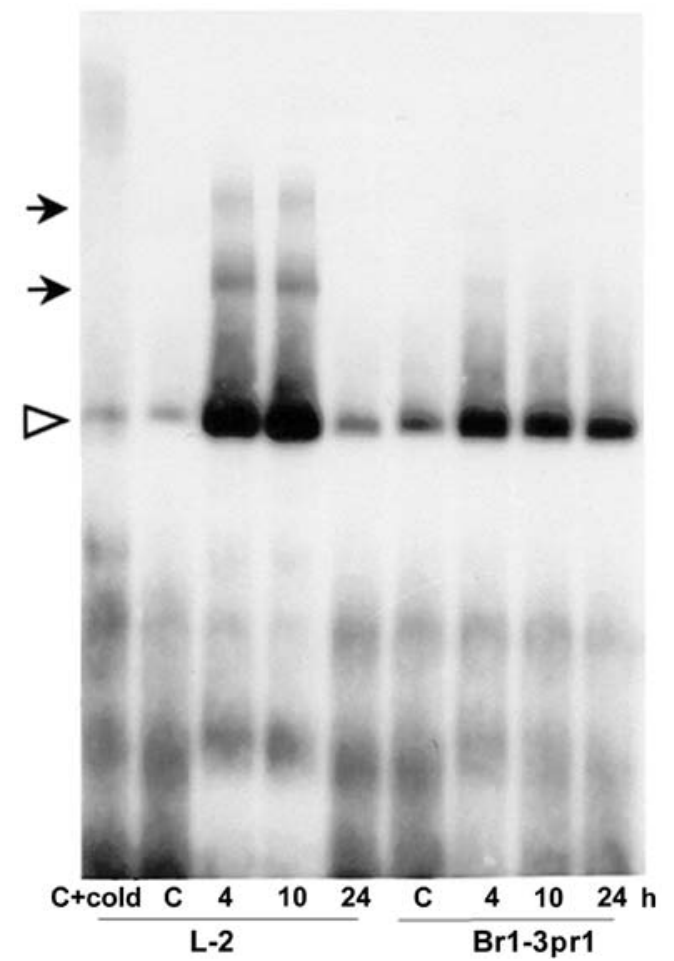

Figure 3. E2F1-DNA binding. Nuclear extracts from untreated control (C) and $300 \mu \mathrm{M}$ PALA treated cells, harvested at 4,10 and $24 \mathrm{~h}$ post-treatment incubated with ${ }^{32} \mathrm{P}$ labeled E2 oligonucleotide displaying E2F1-DNA complex $(\rightarrow)$.

activities, immunoprecipitates of cyclin A, cyclin E, cdc2 and $\operatorname{cdk} 2$ were subjected to HI kinase assays. Quantitation of these data indicated a significant elevation in cyclin A, cyclin $\mathrm{E}$ associated kinase activities in L-2 cells at 4 and $10 \mathrm{~h}$ after PALA removal as compared to the control and there was relatively moderate increase in these kinase activities of Br1-3prl cells (Table II). Cyclin A and E are known to bind both cdK 2 and cdc2, the catalytic subunits $(20,21)$. $\mathrm{Cdk} 2$ and cdc2 kinase activities were markedly elevated in L-2 cells while in Brl-3pr1 cells, only cdk2 kinase was 3x higher post-PALA treatment. In L-2, cdk2 kinase activity was elevated $\sim 9$-fold at $4 \mathrm{~h}$ and 7.5 -fold at $10 \mathrm{~h}$ while cdc2 kinase activity was $\sim 1.6$ - and 2.1 -fold elevated at these time points. The results indicate that higher cyclin $\mathrm{A}, \operatorname{cdc} 2$ associated kinase activities correlated with higher expression levels of these proteins. Cdk2 kinase activity on the other hand was significantly elevated with no apparent increase in the amount of the protein in these cells.

E2F1 DNA binding assay. Cyclin A kinase regulated E2F1 transactivation function has been proposed to represent an S-phase checkpoint that is activated in cells exposed to cytotoxic effects of drugs and ionizing radiation. We assayed for E2F expression and DNA binding activity in untreated and PALA treated cells by gel retardation assay. There was no difference in the level of expression of E2F protein detected in the treated and untreated cells (data not shown). As shown in Fig. 3, E2F complexes (bands shown with solid head arrows) were detected in L-2 cell extracts at 4 and $10 \mathrm{~h}$ post-treatment but were not seen in the control untreated or in the PALA treated Brl-3prl cells. It is important to mention that these
L-2 cells also revealed progressively increasing incidence of apoptosis with enhanced cyclin A expression and associated kinase activities. At $24 \mathrm{~h}$ post-treatment sample, however, the gel retardation assay did not show discrete E2F complexes and only the nonspecific band (shown with open arrowhead) similar to untreated control cell extracts was seen. This might be explained by the fact that at this time, extensive apoptosis in treated cells may have eliminated most of the cells containing E2F with binding affinity for the cognate promoter sequence.

Induction of apoptosis and E2F1-DNA binding in pMTCyc A transfected Brl-3prl cells after PALA and $\mathrm{Zn}^{2+}$ treatment. In order to confirm whether elevated expression of cyclin A in DNA antimetabolite treated cells can mediate or accelerate apoptotic response, stably transfected and conditionally overexpressing cyclin A cell lines were generated by tranfecting Brl-3prl cells with pMTCyc A (Br-lpMTCyc A). Cyclin A expression was induced in Br-lpMTCyc A cells by $100 \mu \mathrm{M}$ $\mathrm{Zn}^{2+}$. Highest level of cyclin A protein expression was consistently achieved after $9 \mathrm{~h}$ induction with $100 \mu \mathrm{M} \mathrm{Zn}{ }^{2+}$ in the clones tested. Fig. 4A demonstrates the inducibility of cyclin A protein in two different clones of Br-lpMTCyc A

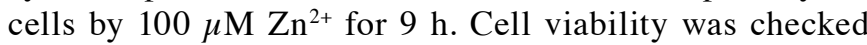
after treatment of cells with $300 \mu \mathrm{M}$ PALA for $48 \mathrm{~h}$ and simultaneous induction of cyclin A with $100 \mu \mathrm{M} \mathrm{Zn}^{2+}$ for $9 \mathrm{~h}$ in the two clones (Br-lpMTCyc A1, Br-lpMTCyc A-2). Cell death was seen at all the time points, with the percentage of apoptotic cells being maximum at $24 \mathrm{~h}$ post-treatment (Fig. 4B). Apoptotic death was further confirmed by DNA fragmentation analysis (Fig. 4C). A time-dependent increase in the DNA fragmentation was noted in both clones from 0-24 h; with maximum fragmentation seen at $24 \mathrm{~h}$. In contrast neither controls nor $\mathrm{Zn}^{2+}$ treated cells displayed presence of oligonucleosomal DNA fragments. Transfected cells, after $48 \mathrm{~h}$ PALA treatment, undergoing apoptosis were analyzed for E2F1-DNA binding activity also by gel retardation assay. As shown in Fig. 4D, E2F-DNA complex was clearly detected in cells induced to express cyclin A in parallel with PALA treatment. Low level E2F binding was also seen in cells treated with PALA in the absence of $\mathrm{Zn}^{2+}$. The data suggested that, even in the absence of $\mathrm{Zn}^{2+}$ induction, slightly elevated cyclin A expression due to leaky regulation of the promoter in the transfected expression vector may have caused low level E2F DNA binding in these cells.

\section{Discussion}

Resistance to chemotherapeutic drugs remains largely unresolved and a germane issue of cancer biology. Molecular events which influence cancer cell sensitivity to chemotherapeutic drugs may include components involved in apoptosis and DNA repair pathways. It has been hypothesized that loss of apoptotic response often leads to chemotherapy resistance in cancer cells. Distinct induction of apoptosis in the L-2 cells and the absence of similar response in the Br1 cells demonstrated that the varying sensitivity to antimetabolite PALA observed in these two cell types was due to the difference in the drug-induced apoptotic response elicited.

It has been established that PALA cytotoxicity is mediated through its inhibitory action on the pyrimidine biosynthetic 
A
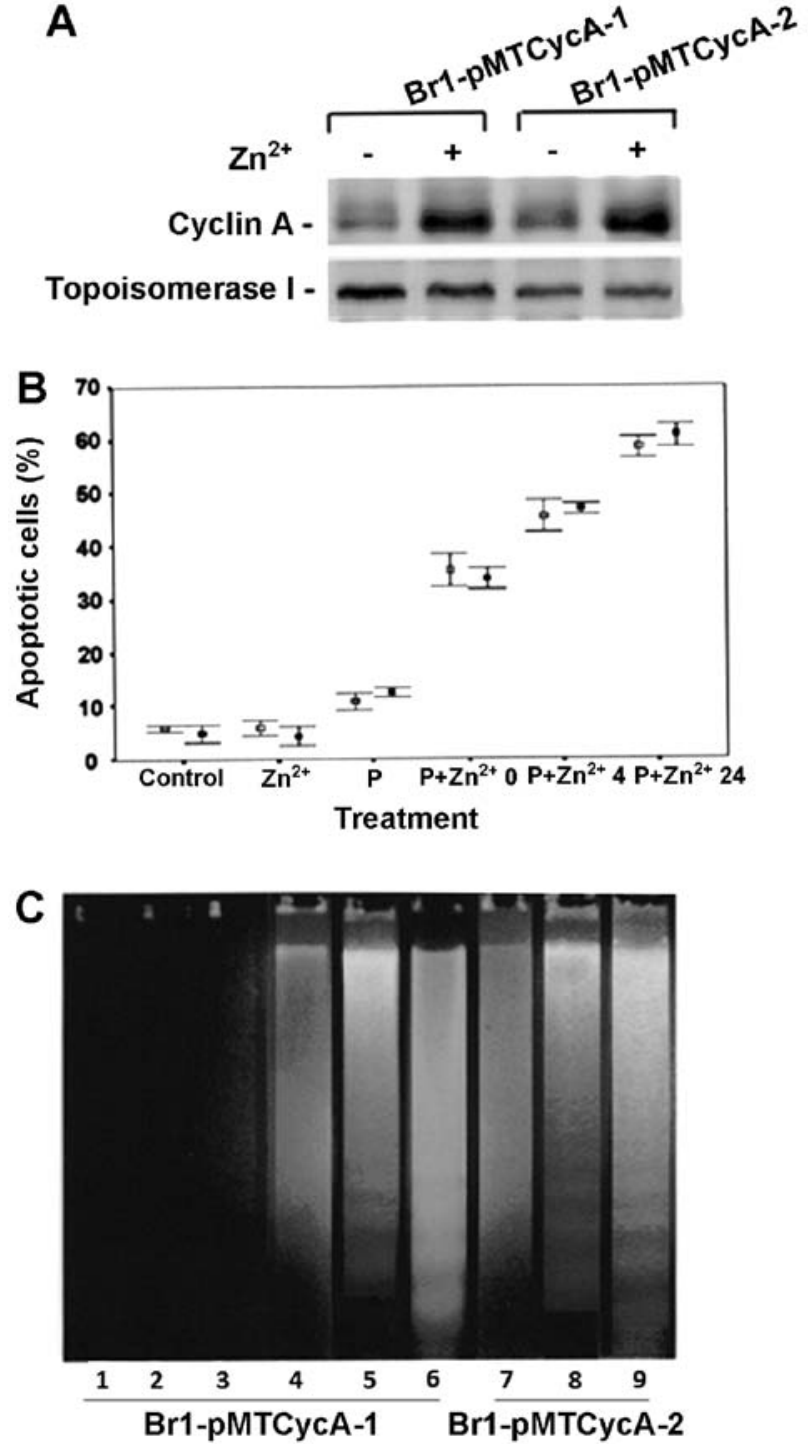

D

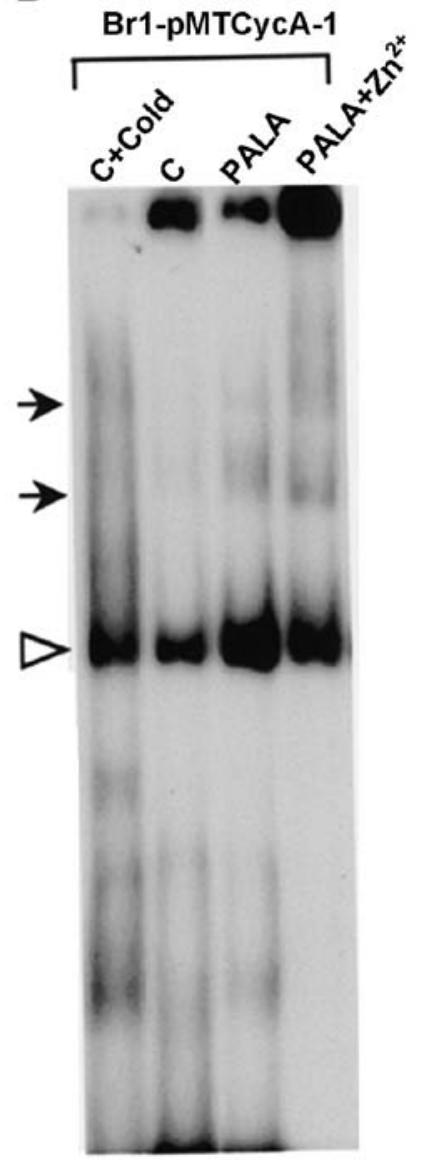

Figure 4. Characterization of inducible cyclin A expressing cells. (A) Cyclin A expression analysis. Brl-pMT Cyc A-1 and Br1-pMT Cyc A-2 cells were treated with $300 \mu \mathrm{M}$ PALA for $48 \mathrm{~h}$ with simultaneous induction of cyclin A with $100 \mu \mathrm{M} \mathrm{Zn}^{2+}$ for $9 \mathrm{~h}$. (B) Percentage of Br1-pMT CycA-1 (open squares) and Br1-pMT CycA-2 (solid squares) cells undergoing apoptosis in controls, $\mathrm{Zn}^{2+}$ alone, PALA alone and PALA $+\mathrm{Zn}^{2+}$ at different time intervals. (C) DNA fragmentation in Br-l pMTCyc A-I and Brl-pMTCyc A-2 cells: Lane 1, Control; 2, Zn ${ }^{2+}$ treated; 3, PALA treated; 4-9, PALA + $\mathrm{Zn}^{2+}$ treated and harvested at $0 \mathrm{~h}$, lanes 4 and 7 ; $4 \mathrm{~h}$, lanes 5 and 8; and $24 \mathrm{~h}$, lanes 6 and 9. (D) E2F1 DNA binding assay in BR 1-pMTCyc A-1 cells: Nuclear extracts from control, $300 \mu \mathrm{M}$ PALA and $300 \mu \mathrm{M}$ PALA $+\mathrm{Zn}^{2+}$ treated cells.

pathway and TAp73-dependent expression of Noxa and Bim (22-24). Hence differential action of PALA on the pyrimidine nucleotides in these cell lines could result in the observed contrast in apoptotic response. To determine if the action of PALA varied in these cell lines, intracellular ribonucleotides were analyzed after incubating cells for $48 \mathrm{~h}$ with $\left(20 x \mathrm{LD}_{50}\right)$ $300 \mu \mathrm{M}$ concentration of the drug. This treatment resulted in a $>90 \%$ decrease in pyrimidine pools, yet the extent of decline was similar in both cell lines. These data and the fact that the isogenic cell lines (Brl cells and cyclin A transfected Brl cells) also varied in their apoptotic response to PALA suggest that this difference is not due to the PALA-mediated alteration in the pyrimidine pools.

Expression of genes such as p53, bcl-2, c-myc and cyclin A are considered critical determinants of apoptotic response in cells (24-27). Cyclin A associated kinase activity has also been reported to be essential for paclitaxel sensitivity of human breast and ovarian cancer cells (28). It has been reported earlier that loss of p53 function in cells leads to resistance to cytotoxic treatments $(29,30)$. Presence of an identical homozygous mutation in p53 in the two cell types (unpublished data) and lack of any perceptible alterations in the expression pattern of the mutant protein following drug treatment suggested that the apoptotic pathway, preferentially activated in the sensitive L-2 cells, was p53 independent.

A number of antitumor agents preferentially induce apoptosis at specific phases of the cell cycle (31-33). Cells undergoing apoptosis frequently do so in late G1 or early S in response to a wide range of stimuli (34-36) indicating that the gene products expressed at these stages may be involved in the activation of apoptotic pathway. Many of the gene products which appear to control apoptotic pathway are regulators of cell cycle progression; thus, cell cycle control and cell death appear to be tightly linked processes (37). Inappropriate activation of 
p34cdc2 kinase has been reported to lead to apoptosis (38). More recently dominant negative mutants of $\mathrm{cdc} 2, \mathrm{cdk} 2$ and cdk3 were found to suppress apoptosis, induced by diverse agents (39), known to be mediated by the active cyclin A kinase complex (40). Elevation in cdk2 and cdc2 kinase activities in L-2 cells undergoing apoptosis therefore reflected their involvement in activation of the apoptotic pathway. Activation of these kinases following induced cyclin A expression in Br-1pMTcyc A cells also suggested that failure to activate cyclin A kinase checkpoint in PALA treated cells allowed Br-l cells to escape apoptosis and proliferate. Induction of apoptosis has earlier been associated with activation of cyclin A dependent kinases but not activity associated with cyclin E or B (40).

It has been reported that overexpression of cyclin A alone in BHK cells cause 'mitotic catastrophes' with chromosomal fragmentation that resembles apoptosis (41). Cyclin A protein has also been implicated in myc-induced apoptosis (27). While our study provides strong evidence in support of cyclin A being a critical determinant of drug-induced apoptosis response, lack of correlation between cyclin A and myc expression suggests that cyclin A mediated apoptotic pathway may be myc independent in these tumor cells. It is however noteworthy that cyclin A kinase activation correlated with higher activity of cyclin E kinase in the L-2 cells. This result may be explained in view of the earlier observation that cyclin E kinase activity precedes and mediates upregulation of cyclin A kinase (42).

Enhanced cyclin A kinase induced apoptotic response, described in this paper, presents an apparent paradox to the concept that cyclin A underlies an $\mathrm{S}$ phase checkpoint that acts through phosphorylation of E2F1, to eliminate E2FI-DNA binding. Phosphorylation of E2Fl regulated by cyclin A/cdk2 in $\mathrm{S}$ phase is known to reduce the ability of the E2F1-DPl heterodimer to bind to DNA and mediate transcriptional transactivation. Mutant E2FI lacking cyclin A/cdk2 binding domain and not phosphorylated by cyclin A/cdk2, prolongs $\mathrm{S}$ phase causing apoptosis and increased sensitivity to the cytotoxic effects of $S$ phase specific agents (43). Inhibition of cyclin A/cdk2 activity causing reduced E2F1 phosphorylation was also shown to increase sensitivity of human tumor cells lacking $\mathrm{pRb}$ to various classes of anticancer drugs (18).

Induction of apoptotic response in the antimetabolite treated cells displaying high cyclin A in parallel with augmented E2F1-DNA binding detected in this study provide contradiction to the above findings and suggests that cyclin A kinase effect on E2F1-DNA binding involves a complex regulatory process. Since cyclin A/cdk2 activation as well as E2Fl transactivation are both required during $\mathrm{Gl}$ to $\mathrm{S}$ transition, it is likely that additional factor(s) such as those required for initiation and/or elongation of DNA-replication modulate the effect of cyclin A kinase on $\mathrm{E} 2 \mathrm{Fl}$ and vice versa. It is relevant here to mention that in vitro studies have convincingly demonstrated that addition of cyclin A alone reconstitutes both kinase activity as well as DNA replication in mammalian $\mathrm{S}$ phase cell extracts and does so by acting at a stage prior to elongation of nascent DNA (44). Although targets of cyclin-dependent kinases at the replication origin remain to be established, the activation pathway may either involve phosphorylation of replication proteins or phosphorylation of downstream kinases. Enhanced expression of cyclin A in drug treated L-2 and Brl-pMTcyc A cells may therefore have activated such downstream effectors of DNA replication to stimulate the elongation process leading to an abortive $S$ phase.

Our results further suggest that such enhanced cyclin A driven replication may also induce increased E2Fl-DNA binding in the cells leading to apoptosis. Low cyclin A activity in drug treated cells, on the contrary, may slow down the replication machinery due to reduced activity of the downstream effectors allowing the cells to complete DNA synthesis without activating an apoptotic response. It is conceivable that inappropriate activation of both E2F1 as well as cyclin A in drug treated cells may induce apoptotic response. Cyclin A kinase, however, may enhance or reduce E2F1-DNA binding based upon the status of effector proteins involved in DNA synthesis. We do not know if loss of apoptotic response seen in drug treated Brl cells occurs due to downregulation of cyclin A gene expression at the transcriptional or translational level. Further elucidation of this mechanism for cyclin A and other cell cycle regulatory proteins involved in activation of drug-induced apoptotic pathways will help identify useful therapeutic targets to overcome drug resistance in tumor cells.

\section{Acknowledgements}

This study was supported by grants from the National Institutes of Health (RO1CA089716 and NCI/EDRN UO1CA111302); University Cancer Foundation, UTMDACC to S.S.

\section{References}

1. Wyllie AH, Kerr JF and Currie AR: Cell death: The significance of apoptosis. Int Rev Cytol 68: 251-306, 1980.

2. Wang J, Chan JY, Fong CC, Tzang CH, Fung KP and Yang M: Transcriptional analysis of doxorubicin-induced cytotoxicity and resistance in human hepatocellular carcinoma cell lines. Liver Int 29: 1338-1347, 2009

3. Sen S and D'Incalci M: Apoptosis. Biochemical events and relevance to cancer chemotherapy. FEBS Lett 307: 122-127, 1992.

4. Colombel M, Olsson CA, Ng PY and Buttyan R: Hormoneregulated apoptosis results from reentry of differentiated prostate cells onto a defective cell cycle. Cancer Res 52: 4313-4319, 1992.

5. Ucker DS: Death by suicide: One way to go in mammalian cellular development? New Biol 3: 103-109, 1991.

6. Katayama H, Wang J, Treekitkarnmongkol W, Kawai H, Sasai K, Zhang H, Wang H, Adams HP, Jiang S, Chakraborty SN, et al: Aurora kinase-A inactivates DNA damage-induced apoptosis and spindle assembly checkpoint response functions of $\mathrm{p} 73$. Cancer Cell 21: 196-211, 2012.

7. Elledge SJ and Spottswood MR: A new human p34 protein kinase, CDK2, identified by complementation of a cdc28 mutation in Saccharomyces cerevisiae, is a homolog of Xenopus Eg1. EMBO J 10: 2653-2659, 1991.

8. Zhu J, Sen S, Wei C and Frazier ML: Cyclin D1b represses breast cancer cell growth by antagonizing the action of cyclin D1a on estrogen receptor $\alpha$-mediated transcription. Int J Oncol 36: 39-48, 2010.

9. Nurse P: Ordering S phase and $\mathrm{M}$ phase in the cell cycle. Cell 79: 547-550, 1994.

10. King RW, Jackson PK and Kirschner MW: Mitosis in transition. Cell 79: 563-571, 1994.

11. Sherr CJ: G1 phase progression: Cycling on cue. Cell 79: 551-555, 1994.

12. Morgan DO: Principles of CDK regulation. Nature 374: 131-134, 1995.

13. Forsburg SL and Nurse P: Cell cycle regulation in the yeasts Saccharomyces cerevisiae and Schizosaccharomyces pombe. Annu Rev Cell Biol 7: 227-256, 1991.

14. DeGregori J, Leone G, Ohtani K, Miron A and Nevins JR: E2F-1 accumulation bypasses a G1 arrest resulting from the inhibition of G1 cyclin-dependent kinase activity. Genes Dev 9: 2873-2887, 1995. 
15. Ikeda MA, Jakoi L and Nevins JR: A unique role for the $\mathrm{Rb}$ protein in controlling E2F accumulation during cell growth and differentiation. Proc Natl Acad Sci USA 93: 3215-3220, 1996.

16. Krek W, Xu G and Livingston DM: Cyclin A-kinase regulation of E2F-1 DNA binding function underlies suppression of an S phase checkpoint. Cell 83: 1149-1158, 1995.

17. Huang Y, Ishiko $T$, Nakada S, Utsugisawa $T$, Kato $T$ and Yuan ZM: Role for E2F in DNA damage-induced entry of cells into S phase. Cancer Res 57: 3640-3643, 1997.

18. Li WW, Fan J, Hochhauser D and Bertino JR: Overexpression of p21waf1 leads to increased inhibition of E2F-1 phosphorylation and sensitivity to anticancer drugs in retinoblastoma-negative human sarcoma cells. Cancer Res 57: 2193-2199, 1997.

19. Price J, Fabra A, Zhang R, Radinsky R and Pathak S: Characterization of variants of a human breast-cancer cell-line isolated from metastases in different organs of nude-mice. Int $\mathbf{J}$ Oncol 5: 459-467, 1994.

20. Graña X and Reddy EP: Cell cycle control in mammalian cells: Role of cyclins, cyclin dependent kinases (CDKs), growth suppressor genes and cyclin-dependent kinase inhibitors (CKIs). Oncogene 11: 211-219, 1995.

21. Elledge SJ, Richman R, Hall FL, Williams RT, Lodgson N and Harper JW: CDK2 encodes a 33-kDa cyclin A-associated protein kinase and is expressed before CDC2 in the cell cycle. Proc Nat Acad Sci USA 89: 2907-2911, 1992.

22. Moyer JD, Smith PA, Levy EJ and Handschumacher RE: Kinetics of $\mathrm{N}$-(phosphonacetyl)-L-aspartate and pyrazofurin depletion of pyrimidine ribonucleotide and deoxyribonucleotide pools and their relationship to nucleic acid synthesis in intact and permeabilized cells. Cancer Res 42: 4525-4531, 1982

23. Grem JL, King SA, O'Dwyer PJ and Leyland-Jones B: Biochemistry and clinical activity of $\mathrm{N}$-(phosphonacetyl)-Laspartate: A review. Cancer Res 48: 4441-4454, 1988.

24. Ruhul Amin AR, Thakur VS, Gupta K, Agarwal MK, Wald DN, Shin DM and Agarwal ML: N-(phosphonacetyl)-L-aspartate induces TAp73-dependent apoptosis by modulating multiple $\mathrm{Bcl}-2$ proteins: Potential for cancer therapy. Oncogene 32 920-929, 2013

25. Katayama H, Sasai K, Kawai H, Yuan ZM, Bondaruk J, Suzuki F, Fujii S, Arlinghaus RB, Czerniak BA and Sen S: Phosphorylation by aurora kinase A induces Mdm2-mediated destabilization and inhibition of p53. Nat Genet 36: 55-62, 2004.

26. Lotem J and Sachs L: Regulation by bcl-2, c-myc, and p53 of susceptibility to induction of apoptosis by heat shock and cancer chemotherapy compounds in differentiation-competent and -defective myeloid leukemic cells. Cell Growth Differ 4: 41-47, 1993.

27. Hoang AT, Cohen KJ, Barrett JF, Bergstrom DA and Dang CV: Participation of cyclin A in Myc-induced apoptosis. Proc Natl Acad Sci USA 91: 6875-6879, 1994.

28. Takahashi T, Yamasaki F, Sudo T, Itamochi H, Adachi S, Tamamori-Adachi M and Ueno NT: Cyclin A-associated kinase activity is needed for paclitaxel sensitivity. Mol Cancer Ther 4: 1039-1046, 2005.

29. Debbas M and White E: Wild-type p53 mediates apoptosis by E1A, which is inhibited by E1B. Genes Dev 7: 546-554, 1993.

30. Lowe SW, Ruley HE, Jacks T and Housman DE: p53-dependent apoptosis modulates the cytotoxicity of anticancer agents. Cell 74: 957-967, 1993.
31. Evans DL and Dive C: Effects of cisplatin on the induction of apoptosis in proliferating hepatoma cells and nonproliferating immature thymocytes. Cancer Res 53: 2133-2139, 1993.

32. Gorczyca W, Gong J, Ardelt B, Traganos F and Darzynkiewicz Z: The cell cycle related differences in susceptibility of HL-60 cells to apoptosis induced by various antitumor agents. Cancer Res 53 3186-3192, 1993.

33. Wang J, Fong CC, Tzang CH, Xiao P, Han R and Yang M: Gene expression analysis of human promyelocytic leukemia HL-60 cell differentiation and cytotoxicity induced by natural and synthetic retinoids. Life Sci 84: 576-583, 2009.

34. Ashwell JD, Cunningham RE, Noguchi PD and Hernandez D: Cell growth cycle block of $\mathrm{T}$ cell hybridomas upon activation with antigen. J Exp Med 165: 173-194, 1987.

35. Howard MK, Burke LC, Mailhos C, Pizzey A, Gilbert CS, Lawson WD, Collins MK, Thomas NS and Latchman DS: Cell cycle arrest of proliferating neuronal cells by serum deprivation can result in either apoptosis or differentiation. J Neurochem 60: 1783-1791, 1993

36. Ryan JJ, Danish R, Gottlieb CA and Clarke MF: Cell cycle analysis of p53-induced cell death in murine erythroleukemia cells. Mol Cell Biol 13: 711-719, 1993.

37. Kastan MB, Canman CE and Leonard CJ: P53, cell cycle control and apoptosis: Implications for cancer. Cancer Metastasis Rev 14: 3-15, 1995.

38. Shi L, Nishioka WK, Th'ng J, Bradbury EM, Litchfield DW and Greenberg AH: Premature p34cdc2 activation required for apoptosis. Science 263: 1143-1145, 1994.

39. Meikrantz W and Schlegel R: Apoptosis and the cell cycle. J Cell Biochem 58: 160-174, 1995.

40. Meikrantz W, Gisselbrecht S, Tam SW and Schlegel R: Activation of cyclin A-dependent protein kinases during apoptosis. Proc Natl Acad Sci USA 91: 3754-3758, 1994.

41. Heald R, McLoughlin M and McKeon F: Human wee1 maintains mitotic timing by protecting the nucleus from cytoplasmically activated Cdc2 kinase. Cell 74: 463-474, 1993.

42. Rudolph B, Saffrich R, Zwicker J, Henglein B, Müller R, Ansorge $\mathrm{W}$ and Eilers M: Activation of cyclin-dependent kinases by Myc mediates induction of cyclin A, but not apoptosis. EMBO J 15: 3065-3076, 1996.

43. Logan TJ, Evans DL, Mercer WE, Bjornsti MA and Hall DJ: Expression of a deletion mutant of the E2F1 transcription factor in fibroblasts lengthens $\mathrm{S}$ phase and increases sensitivity to S phase-specific toxins. Cancer Res 55: 2883-2891, 1995.

44. Fotedar A, Cannella D, Fitzgerald P, Rousselle T, Gupta S, Dorée $\mathrm{M}$ and Fotedar R: Role for cyclin A-dependent kinase in DNA replication in human $\mathrm{S}$ phase cell extracts. J Biol Chem 271: 31627-31637, 1996

45. Gandhi V, Danhauser L and Plunkett W: Separation of 1-beta-D-arabinofuranosylcytosine 5'-triphosphate and 9-betaD-arabinofuranosyl-2-fluoroadenine 5'-triphosphate in human leukemia cells by high-performance liquid chromatography. J Chromatogr A 413: 293-299, 1987.

46. Shirodkar S, Ewen M, DeCaprio JA, Morgan J, Livingston DM and Chittenden T: The transcription factor E2F interacts with the retinoblastoma product and a p107-cyclin A complex in a cell cycle-regulated manner. Cell 68: 157-166, 1992. 